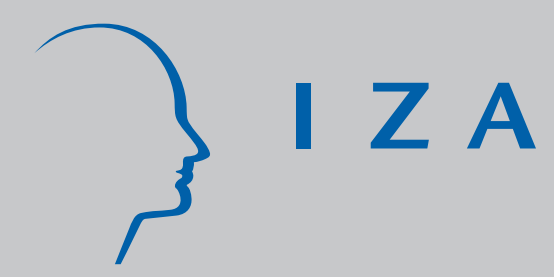

IZA DP No. 790

Hidden Information Problems in the Design of Family Allowances

Alessandro Cigno

Annalisa Luporini

Anna Pettini

J une 2003 


\title{
Hidden Information Problems in the Design of Family Allowances
}

\author{
Alessandro Cigno \\ University of Florence and IZA Bonn \\ Annalisa Luporini \\ University of Florence \\ Anna Pettini \\ University of Florence \\ Discussion Paper No. 790 \\ June 2003 \\ IZA \\ P.O. Box 7240 \\ D-53072 Bonn \\ Germany \\ Tel.: +49-228-3894-0 \\ Fax: +49-228-3894-210 \\ Email: iza@iza.org
}

This Discussion Paper is issued within the framework of IZA's research area Welfare State and Labor Market. Any opinions expressed here are those of the author(s) and not those of the institute. Research disseminated by IZA may include views on policy, but the institute itself takes no institutional policy positions.

The Institute for the Study of Labor (IZA) in Bonn is a local and virtual international research center and a place of communication between science, politics and business. IZA is an independent, nonprofit limited liability company (Gesellschaft mit beschränkter Haftung) supported by the Deutsche Post AG. The center is associated with the University of Bonn and offers a stimulating research environment through its research networks, research support, and visitors and doctoral programs. IZA engages in (i) original and internationally competitive research in all fields of labor economics, (ii) development of policy concepts, and (iii) dissemination of research results and concepts to the interested public. The current research program deals with (1) mobility and flexibility of labor, (2) internationalization of labor markets, (3) welfare state and labor market, (4) labor markets in transition countries, (5) the future of labor, (6) evaluation of labor market policies and projects and (7) general labor economics.

IZA Discussion Papers often represent preliminary work and are circulated to encourage discussion. Citation of such a paper should account for its provisional character. A revised version may be available on the IZA website (www.iza.org) or directly from the author. 
IZA Discussion Paper No. 790

June 2003

\section{ABSTRACT \\ Hidden Information Problems in the Design of Family Allowances*}

We consider a case where some of the parents have higher ability to raise children than others. First-best policy gives both types of parents the same level of utility. If parental actions are not fully observable, however, the policy maker has to take into account the incentive-compatibility constraint that more able parents should not find it profitable to misrepresent their true ability by investing less in their children, and having a lower number of children. The second-best policy induces more able parents to have the first-best number of children, and to invest in each child at the first-best level. Less able parents are induced to have fewer children than in first best, and will underinvest in each child. Whether the government should subsidize more the more able parents, or the less able ones, depends on the properties of the cost function. In second best, however, less able parents will end up with lower utility than more able parents whatever the cost function.

JEL Classification: D13, D82, H31, J13, J24

Keywords: family allowances, parental ability, hidden information, agency problem, optimal taxation

Corresponding author:

Alessandro Cigno

Dipartimento di Studi sullo Stato

University of Florence

Via S. Caterina d'Alessandria, 3

50129 Florence

Italy

Tel.: +3955462 2922

Fax: +3955 472102

Email: cigno@unifi.it

* The paper has benefitted from comments by three anonymous referees, and editorial advice by Junsen Zhang. 


\section{Introduction}

Assuming that the future success or well-being of children is of some interest to the policy maker, and that the future success or well-being of a child depends, to some extent, on the actions and characteristics of the child's parents, differences in parental actions and abilities should be taken into account in the design of policy. ${ }^{1}$ In a broad sense, the relationship between government and parents may thus be seen as an agency problem, with the former in the role of principal and the latter in that of agents.

A couple's ability to raise successful children may be correlated with visible characteristics, such as the couple's educational attainments, geographical location, etc., but it may also reflect parental qualities (warmth, patience, etc.) or conditions (existence of a family network, good social connections), which may not be so easy for the government to observe. We assume that the policy maker has statistical information on the distribution of these qualities and conditions, but does not know who is who.

The optimal policy design presents similarities with an optimal taxation problem, where the government has to persuade workers to reveal their true abilities (dissuade "mimicking"). In the standard optimal taxation literature, however, the aim of government is to raise revenue, or redistribute income. Less conventional optimal taxation problems, such as Balestrino, Cigno and Pettini (2002), take into account parental ability to raise children, as well as ability to raise income, but the government can only observe the number of children, and the income of their parents. Other authors, such as Cremer, Dellis and Pestieau (2003), are concerned with the effect of the number of children, taken as exogenous, on the optimal tax treatment of family size, but they allow parents to differ in earning ability only. Cigno, Luporini and Pettini (2002) examine the case where parents are identical, and the child's well-being depends on a (hidden) parental action and a random factor. Here, we extend the analysis by allowing for differences in parental ability to raise children.

The structure of the problem is as follows. We assume that the child's lifetime utility is a monotone function of some variable, which will become observable when the child is an adult. This variable depends on an action, taken by the child's parents, which is not observable by the government. The cost to the parents of carrying out that action varies across households with some ability parameter, known to the parents themselves, but not to the government (as already mentioned, the government knows only the statistical distribution of this parameter in the population of parents). Parents choose how much to invest in each child, and possibly how many children to have, taking government policy as given. We pose the question whether it is optimal for the policy maker to interfere with parental choices, and in which way. Should public policy help disadvantaged parents (those with lower ability), or provide incentives to the more efficient ones? Should transfers to families be conditional on number of

\footnotetext{
${ }^{1}$ For a general discussion of the factors entering an optimal policy towards households with children, see Cigno (2001).
} 
children, or on the child's lifetime income? If the number of children is a choice variable, should the policy encourage more able parents to have more children?

\section{Parental choice}

Let $a$ denote the consumption of present adults (parents). Let $x$ be the present value of a child's future tax payments. Given the tax system and the rate of interest, the variable $x$ is a monotonic function of the child's lifetime income stream. Parents are assumed to derive utility from their own consumption, $a$. They may also derive utility from the number of children, and from the wellbeing of each child (proxied by $x$ ). Let $z(x)$ be the monetary equivalent of the utility that parents derive from a child with tax paying capacity $x$. The function $z($.$) will be increasing and concave. Parental utility is U(a+z(x))$, where $U($. is assumed concave.

Let $\theta$ be a productivity parameter, variable across households, representing parental ability to raise children. The cost of raising $n$ children with ability to pay taxes $x$, in households with parental ability $\theta$, is given by

$$
C(n, x, \theta)=c(n)+f(x, \theta) s(n) .
$$

The term $c(n)$ may be interpreted as the survival cost of $n$ children. This element of cost includes not only the actual expenses, but also the opportunitycosts of parental time and other fixed household resources, necessary to bring into the world and keep alive that number of children. The function $c($.$) will thus$ be increasing, but may be either concave or convex. Concavity would imply that some of these fixed household resources can be shared among siblings, convexity that they are subject to crowding.

The term $f(x, \theta)$ represents the cost, to parents of ability $\theta$, of providing a child with the lifetime income stream reflected in $x$. This term is clearly increasing and convex in $x$ (diminishing returns to educational investment), and decreasing in $\theta$. The assumption that not only $f$, but also $f_{x}$ is decreasing in $\theta$ ensures that the indifference curves of households with different $\theta$ do not cross more than once in the $(a, x)$ plane. The multiplicative factor $s(n)$, is clearly increasing in $n$, but could be either concave or convex. As in the case of the survival costs, concavity would imply that some element of the educational investments, including parental time, which contribute to the production of $x$ can be shared among siblings; convexity would imply that these investments are subject to crowding.

These considerations allow us to sign all the first and second derivatives of the functions figuring in (1),

$$
c^{\prime}>0, f_{x}>0, f_{\theta}<0, s^{\prime}>0, f_{x \theta}<0 \text { and } f_{x x}>0,
$$

other than $c^{\prime \prime}$ and $s^{\prime \prime}$. If $n$ is a choice variable, however, the marginal cost of children must be increasing in the number of children above some level of $n$, lower than the physiological maximum. Were that not true, we would in fact 
observe that, in laissez faire, parents have as many children as nature permits (and would like to have even more). It must then be the case that diseconomies of scale ${ }^{2}$ set in,

$$
C_{n}=c^{\prime \prime}+f s^{\prime \prime}>0,
$$

before the physiological maximum is reached.

Let $m$ be the parents full after-tax income. Let $y$ be a per-child government transfer to parents, possibly conditional on $x$ and $n .^{3}$ This implies that the transfer schedule need not, and typically will not, be linear. The household budget constraint is

$$
a=m+y(n, x) n-c(n)-f(x, \theta) s(n) .
$$

In view of this constraint, parental utility is given by

$$
U(m+[y(x)+z(x)] n-f(x, \theta) s(n)-c(n)) .
$$

Parents choose $x$, and possibly $n$. Following a well-established procedure, we assume that the government faces parents with a menu of possible choices. The choice is between two $(y, x)$ pairs if fertility is exogenous, between two $(y, x, n)$ triplets if fertility is endogenous. Parents choose the alternative that gives them the highest utility.

\section{Policy design}

Assume that the policy maker's objective is to maximize the sum of the utilities of current adults (its electors). ${ }^{4}$ For simplicity, we take it that $\theta$ takes only two values, $\theta_{1}$ and $\theta_{2},{ }^{5}$ with $\theta_{1}<\theta_{2}$. Let $p=\operatorname{Pr}\left(\theta=\theta_{1}\right)$ represent the proportion of households with low ability to rear children. In a first-best world, the policy maker knows which household has which value of $\theta$. In second best, the government knows only how the parameter $\theta$ is distributed across households. Let $x_{i} \equiv x\left(\theta_{i}\right), n_{i} \equiv n\left(\theta_{i}\right)$ and $y_{i} \equiv y\left(n_{i}, x_{i}\right), i=1,2$. Selecting a transfer schedule $y($.$) conditional on the information that is either available now, or will become$ available in the future, is the same as choosing $\left(y_{1}, y_{2}, x_{1}, x_{2}, n_{1}, n_{2}\right)$. Assuming that the number of households is large enough for each couple of parents to take

\footnotetext{
${ }^{2}$ Evidence of economies or diseconomies of scale in child rearing is limited. Early evidence is surveyed in Cigno (1991, ch. 6). More recent evidence is reported in Deaton and Paxson (1995), Gazely and Newell (2000), Iceland (2000). While some of the earlier studies find monetary expenditure per child increasing with the number of children, and some report time expenditures per child decreasing as the number goes up, others show these costs to be rougly invariant with the number of children. The more recent studies, all motivated by the measurement of poverty, are equally inconclusive. The only clear evidence of (modest) economies of household size refers to non-family households (cohabiting or unrelated adults), and is thus not applicable to child rearing.

${ }^{3}$ See the concluding section for a discussion of the timing of this transfer.

${ }^{4}$ Alternatively, we can interpret this as a problem of choice between alternative steady states, and take $U$ to be the utility of the representative agent.

${ }^{5}$ Our results can be easily generalized to the case in which $\theta$ can take more than two values, and to the one in which $\theta$ is a continuous variable.
} 
the schedule as given, the solution to the policy optimization problem confronts each household with a straight choice between two alternatives, $\left(y_{1}, x_{1}, n_{1}\right)$ or $\left(y_{2}, x_{2}, n_{2}\right)$.

Under conditions of hidden information, the policy maker will select the transfer schedule so as to maximize its own objective function,

$$
\begin{aligned}
W= & p U\left\{m+\left[y_{1}+z\left(x_{1}\right)\right] n_{1}-f\left(x_{1}, \theta_{1}\right) s\left(n_{1}\right)-c\left(n_{1}\right)\right\}+ \\
& (1-p) U\left\{m+\left[y_{2}+z\left(x_{2}\right)\right] n_{2}-f\left(x_{2}, \theta_{2}\right) s\left(n_{2}\right)-c\left(n_{2}\right)\right\} .
\end{aligned}
$$

In first best, the only constraint on the choice of policy is the intergenerational budget constraint,

$$
p x_{1} n_{1}+(1-p) x_{2} n_{2} \geq p y_{1} n_{1}+(1-p) y_{2} n_{2} .
$$

In second best, however, the policy maker must guard against the possibility of mimicking. The optimization is then subject also to the incentive compatibility constraint that each household should prefer the transfer intended for its own type, to the one intended for the other,

$$
\begin{gathered}
{\left[y_{1}+z\left(x_{1}\right)\right] n_{1}-f\left(x_{1}, \theta_{1}\right) s\left(n_{1}\right)-c\left(n_{1}\right) \geq} \\
{\left[y_{2}+z\left(x_{2}\right)\right] n_{2}-f\left(x_{2}, \theta_{1}\right) s\left(n_{2}\right)-c\left(n_{2}\right),} \\
\\
{\left[y_{2}+z\left(x_{2}\right)\right] n_{2}-f\left(x_{2}, \theta_{2}\right) s\left(n_{2}\right)-c\left(n_{2}\right) \geq} \\
{\left[y_{1}+z\left(x_{1}\right)\right] n_{1}-f\left(x_{1}, \theta_{2}\right) s\left(n_{1}\right)-c\left(n_{1}\right) .}
\end{gathered}
$$

Coherently with the assumption that the policy maker is only interested in the utilities of current adults, the government budget constraint (7) implies that future tax revenues are redistributed among present tax payers in the form of child-related subsidies. Notice, also, that (7) differs from the household budget constraint (4) in that the latter does not take into account the children's future contributive capacity. That is because each child's future tax payments are too small a fraction of the government's total future revenue for that child's parents to perceive the benefit in terms of higher transfers. If the direct utility that parents derive from their children's future income does not exactly match the social benefit in terms of future tax revenue, there is then an externality. We take this externality to be positive, $z(x)<x$.

\subsection{Exogenous fertility}

If fertility is exogenous, parents choose the level of the investment in each child (and, therefore, $x$ ), taking the number of children as given. As there is no reason to expect a correlation (positive or negative) between the exogenously given number of children and the exogenously given ability to give children a good start in life, we assume $n_{1}=n_{2}=n$. 
The first-best policy maximizes (6) subject to (7), obviously binding. The first-order conditions tell us that

$$
\left[1+z^{\prime}\left(x_{i}\right)\right] n_{i}=f_{x}\left(x_{i}, \theta_{i}\right) s\left(n_{i}\right), i=1,2 .
$$

In other words, $x_{i}$ must be set at a level that equalizes its marginal social cost to its marginal social benefit. Indicating by $x_{i}^{*}$ the first-best value of $x_{i},(10)$ implies

$$
x_{1}^{*}<x_{2}^{*} .
$$

Since the first-order conditions equalize the marginal utilities of the two household types, private surpluses are equalized,

$$
\begin{gathered}
{\left[y_{1}+z\left(x_{1}\right)\right] n_{1}-f\left(x_{1}, \theta_{1}\right) s\left(n_{1}\right)-c\left(n_{1}\right)=} \\
{\left[y_{2}+z\left(x_{2}\right)\right] n_{2}-f\left(x_{2}, \theta_{2}\right) s\left(n_{2}\right)-c\left(n_{2}\right) .}
\end{gathered}
$$

Notice that, since $n_{1}=n_{2},(12)$ implies $y_{1}^{*}>x_{1}^{*}$ and $y_{2}^{*}<x_{2}^{*}$, where $y_{i}^{*}$ denotes the first-best value of $y_{i}$. Besides redistributing utility from the future to the current generation of tax payers, the policy thus performs an intra-generational redistribution from more to less able parents. Can we say whether, at the optimum, $y_{1}$ is larger or smaller than $y_{2}$ ? Depending on the shape of the $z($.$) and f($.$) functions, the net cost of endowing each child with the$ required lifetime income, $f\left(x_{i}^{*}, \theta_{i}\right) s(n)+c(n)-z\left(x_{i}^{*}\right) n$, can be higher for either the low or the high-ability parents. Thus, in general, the optimal $y_{1}$ could be either lower or higher than the optimal $y_{2}$. Let us see if we can establish conditions for $y_{1}^{*}>y_{2}^{*}$.

Given (10), $x^{*}$ is implicitly a function of $\theta$. In view of (2),

$$
\frac{d x^{*}}{d \theta}=-\frac{\sigma f_{x \theta}}{\sigma f_{x x}-z^{\prime \prime}}>0,
$$

where $\sigma \equiv \frac{s(n)}{n}$.

Define $\phi(\theta)=z\left(x^{*}\right)-f\left(x^{*}, \theta\right) \sigma$. Clearly, $y_{1}^{*}>y_{2}^{*}$ if and only if $\phi\left(\theta_{1}\right)<$ $\phi\left(\theta_{2}\right)$. Since

$$
\phi^{\prime}(\theta)=\left(z^{\prime}-f_{x} \sigma\right) \frac{d x^{*}}{d \theta}-\sigma f_{\theta},
$$

and, using (10), it is then optimal to set $y_{1}$ greater than $y_{2}$ if and only if

$$
\frac{d x^{*}}{d \theta}<-\sigma f_{\theta} .
$$

In words, a necessary and sufficient condition for the less able parents to receive a larger per-child subsidy than the more able ones is that $\theta$ raises future income for the child (and thus tax receipts for the government) less than it reduces costs for the child's parents. Using (13), (14) can also be written as

$$
\frac{x}{f_{\theta}} f_{\theta x}<\frac{x}{\sigma f_{x}-z^{\prime}}\left(\sigma f_{x x}-z^{\prime \prime}\right),
$$


meaning that the $x$-elasticity of the private marginal benefit of $\theta$ must be lower than the $x$-elasticity of the private marginal cost (both on a per-child basis). This imposes restrictions on the form of $f($.$) and z(.){ }^{6}$

The second-best policy satisfies also the incentive compatibility constraints (8) and (9). Using standard techniques, ${ }^{7}$ it can be shown that the government budget constraint (7), and the incentive-compatibility constraint on the more able type (9), will be binding, but the incentive-compatibility constraint on the less able type (8) will not. Hence,

$$
\begin{aligned}
& s\left(n_{2}\right) f_{x}\left(x_{2}, \theta_{2}\right)=\left[1+z^{\prime}\left(x_{2}\right)\right] n_{2}, \\
& s\left(n_{1}\right) f_{x}\left(x_{2}, \theta_{1}\right)<\left[1+z^{\prime}\left(x_{1}\right)\right] n_{1},
\end{aligned}
$$

implying

$$
x_{1}<x_{1}^{*}<x_{2}=x_{2}^{*} .
$$

This is the usual no-distortion-at-the-top result. In order to discourage type- 2 parents from pretending to be type 1 by underinvesting in their children, type- 1 parents are required to endow their children with less than the first-best level of lifetime income. Since type-1 parents have no interest in pretending to be of type 2 , the latter are still required to endow their children with the first-best level of lifetime income.

The fact that (9) is binding further implies

$$
\begin{gathered}
{\left[y_{1}+z\left(x_{1}\right)\right] n_{1}-c\left(n_{1}\right)-f\left(x_{1}, \theta_{1}\right) s\left(n_{1}\right)<} \\
{\left[y_{2}+z\left(x_{2}\right)\right] n_{2}-c\left(n_{2}\right)-f\left(x_{2}, \theta_{2}\right) s\left(n_{2}\right) .}
\end{gathered}
$$

It is no longer true, therefore, that the marginal utility of income is equalized across household types, and that the two types get the same level of utility. In second best, clever parents get higher utility than less clever ones.

Can we say anything about the second-best levels of $y_{1}$ and $y_{2}$ ? If $y_{2}-y_{1}$ is positive in first best, it will be more positive in second best, because clever parents must be dissuaded from mimicking. For the same reason, if $y_{2}-y_{1}$ is negative in first best, it will be less negative, and may become positive, in second best. If low-ability parents are to be subsidized more than high-ability ones in first best, we cannot then say which of the two types should be subsidized more in second best.

\subsection{Endogenous fertility}

Let us now suppose that parents control the number of births. In first best, (10) will still hold (but remember that $n_{1}$ may now be different from $n_{2}$ ). Addition-

\footnotetext{
${ }^{6}$ As an example, suppose that $z(x) \equiv 0$. The condition for the low-ability parents to be subsidized more than the high-ability ones is satisfied if $f(x, \theta)=x^{2}-\theta x$, but not if $f(x, \theta)=\frac{x^{2}}{\theta}$.

${ }^{7}$ See, for example, Macho-Stadler and Perez-Castrillo (1997).
} 
ally, we have first-order conditions on $n_{i}$, yielding

$$
\left[x_{i}+z\left(x_{i}\right)-f\left(x_{i}, \theta_{i}\right) s^{\prime}\left(n_{i}\right)\right]=c^{\prime}\left(n_{i}\right), i=1,2,
$$

Jointly, (19) and (10) define an implicit relationship between the first-best values of $n_{i}$ and $x_{i},\left(n_{i}^{*}, x_{i}^{*}\right)$, and the parental ability parameter $\theta_{i}$, with

$$
\begin{aligned}
& \frac{\partial n_{i}^{*}}{\partial \theta_{i}}=-n_{i}^{*} \frac{f_{x} f_{x \theta} \sigma_{i}^{2}\left(1-\frac{s \prime}{\sigma_{i}^{*}}\right)+f_{\theta} s^{\prime}\left(f_{x x} \sigma_{i}-z^{\prime \prime}\right)}{H_{i}}, \\
& \frac{\partial x_{i}^{*}}{\partial \theta_{i}}=-\sigma_{i} \frac{n_{i}^{*} f_{x \theta}\left(c^{\prime \prime}+f s^{\prime \prime}\right)+f_{x} f_{\theta} s^{\prime}\left(1-\frac{s \prime}{\sigma_{i}}\right)}{H_{i}},
\end{aligned}
$$

where $H_{i}$ is the bordered Hessian determinant, positive for second-order conditions, and $\sigma_{i} \equiv \frac{s\left(n_{i}^{*}\right)}{n_{i}^{*}}$. The signs of both these derivatives are ambiguous in general. The terms $f_{\theta} s^{\prime}\left(f_{x x} \sigma_{i}-z^{\prime \prime}\right)$ and $n_{i}^{*} f_{x \theta}\left(c^{\prime \prime}+f s^{\prime \prime}\right)$ are unambiguously negative for $(2)-(3)$. The term $\left(1-\frac{s \prime}{\sigma_{i}}\right)$ can be positive or negative, depending on whether the production of $x_{i}$ is characterized by economies or diseconomies of scale (measured in number of children). ${ }^{8}$ Therefore, (20) and (21) are clearly positive for $\left(1-\frac{s \prime}{\sigma_{i}}\right) \geq 0$, ambiguous for $\left(1-\frac{s \prime}{\sigma_{i}}\right)<0$.

We have thus found that the optimal number of children, and the optimal investment per child, increase with parental ability in the presence of economies of scale in the educational process (suggesting that educational inputs are a kind of local public good). But the same may be true even in the presence of diseconomies (suggesting that educational inputs are impure public goods, subject to "crowding") provided they are not too strong. Supposing (20) and (21) to be positive, the first-order conditions imply

$$
x_{1}^{*}<x_{2}^{*}, n_{1}^{*}<n_{2}^{*} .
$$

As in the exogenous fertility case, clever parents must then invest more in each child than less clever parents. Additionally, however, clever parents must now have more children. Since the marginal utility of income is still equalized across household types, (12) must hold as in the exogenous fertility case (but this time with $n_{1}<n_{2}$ ).

Let us look for conditions such that $y_{1}^{*}>y_{2}^{*}$ in the case where fertility is endogenous. Define $\Phi(\theta) \equiv z\left(x^{*}\right) n^{*}-f\left(x^{*}, \theta\right) s\left(n^{*}\right)$. The less able parents must now be subsidized more than the more able ones if and only if

$$
\Phi^{\prime}(\theta)=\left(z^{\prime} n^{*}-f_{x} s\right) \frac{\partial x^{*}}{\partial \theta}+\left(z-f s^{\prime}-c^{\prime}\right) \frac{\partial n^{*}}{\partial \theta}-s f_{\theta}>0 .
$$

\footnotetext{
${ }^{8}$ We are talking of the cost of providing each child with any given level of $x$ increasing more or less than in proportion to $n$. In view of (3), any economies in educational costs must be more than offset by diseconomies in the other element of the overall cost of rearing children.
} 
In view of first-order conditions (10) and (19), this implies

$$
\frac{d X^{*}}{d \theta} \equiv n^{*} \frac{\partial x^{*}}{\partial \theta}+x^{*} \frac{\partial n^{*}}{\partial \theta}<-s f_{\theta},
$$

where $X \equiv n x$. In words, a necessary and sufficient condition for the less able parents to receive a higher per-child subsidy than the more able ones is that $\theta$ raises future thus tax receipts for the government, less than it reduces costs for the parents (all on a per-household basis).

In second best, (17) holds as in the exogenous fertility case. It also remains true that the marginal utility of income is lower for the more able parents, again implying (18). The first-order conditions further imply

$$
\begin{aligned}
& x_{2}+z\left(x_{2}\right)-f\left(x_{2}, \theta_{2}\right)=c^{\prime}\left(n_{2}\right), \\
& x_{1}+z\left(x_{1}\right)-f\left(x_{1}, \theta_{1}\right)>c^{\prime}\left(n_{1}\right) .
\end{aligned}
$$

Therefore, we have again the no-distortion-at-the-top result. Here, however, this property applies not only to the choice of $x$, but also to that of $n$. Now, fertility choice is distorted for the less able parents. ${ }^{9}$ This last result could be interpreted as meaning that, in order to discourage mimicking by clever parents, less clever ones must be induced to have fewer children (as well as investing less in each one of them) than in first best.

\section{Discussion}

The assumption that parents do not fully internalize the social benefit of raising children, and giving each child a good start in life, lead us to the conclusion that parents should be subsidized. Allowing for household differentiation by parental ability to raise successful children, we find that child-related subsidies should be made conditional on available measures or predictors of a child's future wellbeing. If the number of children is a choice variable, the transfer scheme should take account also of the number of children.

As usual, the first-best policy reflects both equity and efficiency considerations. ${ }^{10}$ If households differed in their incomes, as in conventional models, equity would imply redistributing from the rich to the poor. In our model, however, households differ in the cost of raising successful children, and equity thus implies redistributing from more to less able parents. In the exogenous fertility case, that shows up in the difference between the surplus produced by a child

\footnotetext{
${ }^{9}$ We have imposed conditions such that the optimization has an interior solution, but the proposition that $n_{1}$ should be distorted applies even if the first best is at a corner. Suppose that, $n_{1}^{*}=n_{2}^{*}=\bar{n}$, where $\bar{n}$ is the physiological maximum. If the government were to require either household to have less than $\bar{n}$ children, that would reduce the household's utility. If the government were to require type 1 to have less than $\bar{n}$ children, $f\left(x_{1}, \theta_{2}\right) s\left(n_{1}\right)$ would fall less than $f\left(x_{1}, \theta_{1}\right) s\left(n_{1}\right)$, thereby relaxing the incentive-compatibility constraint. It remains true that $x_{1}<x_{1}^{*}$ also helps to relax that constraint.

${ }^{10}$ Given Benthamite preferences like (6), the government is obviously indifferent to utility inequality, but maximizing a sum of concave utility functions implies redistributing income from households with lower marginal utility, to households with higher marginal utility.
} 
in a high-ability household, and the surplus produced by a child in a low-ability one. ${ }^{11}$ In the endogenous fertility case, it shows up in the difference between the total surplus produced by all the children of a couple of high-ability parents and that produced by all the children of a low-ability couple.

In first best, redistribution in favour of the less able can be achieved without distorting incentives. In second best, redistribution gives rise to the problem that the more able parents could have an interest in pretending to be less able. Therefore, the less able parents must be induced to have fewer children than in first best in order to discourage mimicking. Depending on the properties of the cost-of-children function, it may be optimal to subsidize less able parents at a higher rate per child than more able parents, or the other way round. The policy maker could find out which is the case experimentally by initially setting $y_{1}=y_{2}$. If, say, it observes that parents whose children have a higher propensity to go to university have fewer children, that is a sign that $y_{2}$ should be raised. ${ }^{12}$

It may be interesting to compare these results with similar attempts at establishing a relationship between child subsidies, family size, and parental ability. Cremer, Dellis and Pestieau (2003) find that the rate of subsidy should increase with the number of children. We, by contrast, find that things could go either way depending on the properties of the cost function. But the two findings are not directly comparable, because C-D-P take fertility as exogenous (and households to be differentiated by parental income only). We, by contrast, take fertility and the rate of subsidy per child to be co-determined (and households to be differentiated by ability to raise children only).

Balestrino, Cigno and Pettini (2002) use a household decision model similar to the present one to derive optimal taxation rules. They find that fertility decisions are distorted, in the second-best optimum, not in order to deter mimicking, but only in order to re-distribute income. Why is that not true in our case? The reasons appear to be two. One is that, in B-C-P, the child's utility is not observable (while, in our model, a proxy of this variable is). The other is that, in our model, the government has an intergenerational budget constraint, while B-C-P's analysis is static. The presence of this intergenerational budget constraint generates a positive externality, that gives the government a direct interest in the number and well-being of future adults. The observability of both makes it feasible to directly subsidize them.

Cigno, Luporini and Pettini (2002) find that the optimal transfer depends only on the child's lifetime income (the proxy for the child's future well-being). That is simply because C-L-P assume parents to have the same ability to raise children, so that the number of children in a household does not convey information on the characteristics of their parents. Ability differences are thus relevant for the design of policy.

Our finding that it is optimal to condition transfers on both the number of children, and some indicator of a child's future well-being, need not be read as

\footnotetext{
${ }^{11}$ Actual equality beween the two surpluses is achieved only in the first best. In second best, this may be prevented by the incentive-compatibility constraints, and there is only a tendency to make this difference smaller.

${ }^{12}$ We a greatful to one of the referees for suggesting this to us.
} 
literally meaning that each household should receive a single payment, calculated on the basis of both household characteristics. The government might in fact find it expedient to use two separate policy instruments, one conditional on the number of children, and the other on some measure, or predictor, of the lifetime income of each child. If it does, however, it must still determine the two instruments simultaneously, and announce the rules before would-be parents make their decisions.

Separate instruments have the advantage that they can be timed differently. As the first part of the transfer requires no more information than a head count, it can in fact be administered while children are still very young. This would then constitute a family allowance as commonly understood. The second part of the transfer, by contrast, requires information on a child's ability to raise income, which can be more accurately assessed later in the child's life. It could then take the form of a scholarship for the child, ${ }^{13}$ or of a pension entitlement for the parents. ${ }^{14}$ The latter is suggested by Cigno, Luporini and Pettini (2002) in an uncertainty context, where the outcome of the hidden parental action is a random variable. The suggestion remains valid in a certainty context where the outcome depends on an ability parameter, known to the parents but not to the policy maker. ${ }^{15}$

The problem with paying part of the subsidy a long time after the child's birth is that parents may not take the subsidy fully into account when taking their decision to have children and expend household resources on them. However, public concern about the ability of public pension systems to deliver the hoped-for benefits, and recent reforms aimed at making a person's pension benefits more closely related to his or her pension contributions, have raised individual consciousness of the link between current decisions and future outcomes in this sphere. Paradoxically, therefore, the idea of making part of the child-related subsidy payable in the form of an additional pension benefit when the child is in middle life (and the parents are on the point of retiring) could present fewer drawbacks than that of making the payment in the form of a scholarship when the child is about to enter secondary school or university (and parents are still relatively young).

\footnotetext{
${ }^{13}$ Whether the scholarship is paid to the parents, or directly to the child, it still reduces the cost to the parents of investing in that child.

${ }^{14}$ Many real-life public pension systems make part of the pension entirtlements of women positively dependent on number of children, or on time spent away from the labour markets to raise children. In some systems, the allowance takes account also of the mother's ability (albeit, ability to raise income, not children). Progressive income taxation, or pension rules that base the benefit on "the best years" in the pensioner's working life, also unwittingly allow parents to shift part of the burden of raising children on to other workers.

${ }^{15}$ The social optimality of using pension and child benefits jointly as instruments of policy is pointed out in Peters (1995), Kolmar (1997), Groezen, Leers and Meijdam (2002).
} 


\section{$5 \quad$ References}

Balestrino, A., Cigno, A. and A. Pettini (2002), "Endogenous Fertility and the Design of Family Taxation", International Tax and Public Finance 9, 173-191

Cigno, A. (1991), Economics of the Family, Oxford and New York: Clarendon Press and Oxford University Press

- (2001), "Comparative Advantage, Observability and the Optimal Tax Treatment of Families with Children", International Tax and Public Finance 8, $455-470$

—- Luporini, A. and A. Pettini (2003), "Transfers to Families with Children as a Principal-Agent Problem", Journal of Public Economics 87, 1165-1177

Cremer, H., Dellis, A. and P. Pestieau (2003), "Family Size and Optimal Income Taxation", Journal of Population Economics, forth.

Deaton, A. and C. Paxson (1995), "Measuring poverty among the Elderly", NBER Working Paper 5296

Gazely, I. and A. Newell (2000), "Rowntree Revisited: Poverty in Britain, 1900", Explorations in Economic History 37, 174-88

Groezen, B. van, Leers, T. and L. Meijdam (2002), "Social Security and Endogenous Fertility: Pensions and Child Allowances as Siamese Twins", Journal of Public Economics (forth.)

Iceland , J. (2000), "The Family/Couple/Household Unit of Measurement in Poverty Estimation", Journal of Economic and Social Measurement 26, 253-65

Kolmar, M. (1997), "Intergenerational Redistribution in a Small Open Economy with Endogenous Fertility", Journal of Population Economics 10, 335-356

Macho-Stadler, I. and D. Perez-Castrillo (1997), An Introduction to the Economics of Information, Oxford University Press, Oxford.

Peters, W. (1995), "Public Pensions, Family Allowances and Endogenous Demographic Change", Journal of Population Economics 8, 161-183 


\section{IZA Discussion Papers}

\begin{tabular}{|c|c|c|c|c|}
\hline No. & Author(s) & Title & Area & Date \\
\hline 775 & $\begin{array}{l}\text { J. J. Heckman } \\
\text { L. J. Lochner } \\
\text { P. E. Todd }\end{array}$ & Fifty Years of Mincer Earnings Regressions & 5 & $05 / 03$ \\
\hline 776 & $\begin{array}{l}\text { L. Arranz-Aperte } \\
\text { A. Heshmati }\end{array}$ & $\begin{array}{l}\text { Determinants of Profit Sharing in the Finnish } \\
\text { Corporate Sector }\end{array}$ & 2 & $05 / 03$ \\
\hline 777 & $\begin{array}{l}\text { A. Falk } \\
\text { M. Kosfeld }\end{array}$ & $\begin{array}{l}\text { It's all about Connections: Evidence on Network } \\
\text { Formation }\end{array}$ & 6 & $05 / 03$ \\
\hline 778 & F. Galindo-Rueda & $\begin{array}{l}\text { Employer Learning and Schooling-Related } \\
\text { Statistical Discrimination in Britain }\end{array}$ & 5 & $05 / 03$ \\
\hline 779 & M. Biewen & $\begin{array}{l}\text { Who Are the Chronic Poor? Evidence on the } \\
\text { Extent and the Composition of Chronic Poverty } \\
\text { in Germany }\end{array}$ & 1 & $05 / 03$ \\
\hline 780 & $\begin{array}{l}\text { A. Engellandt } \\
\text { R. T. Riphahn }\end{array}$ & Temporary Contracts and Employee Effort & 1 & $05 / 03$ \\
\hline 781 & $\begin{array}{l}\text { J. H. Abbring } \\
\text { J.R. Campbell }\end{array}$ & $\begin{array}{l}\text { A Structural Empirical Model of Firm Growth, } \\
\text { Learning, and Survival }\end{array}$ & 5 & $05 / 03$ \\
\hline 782 & $\begin{array}{l}\text { M. Güell } \\
\text { B. Petrongolo }\end{array}$ & $\begin{array}{l}\text { How Binding Are Legal Limits? Transitions from } \\
\text { Temporary to Permanent Work in Spain }\end{array}$ & 1 & $05 / 03$ \\
\hline 783 & $\begin{array}{l}\text { B. T. Hirsch } \\
\text { E. J. Schumacher }\end{array}$ & $\begin{array}{l}\text { Match Bias in Wage Gap Estimates Due to } \\
\text { Earnings Imputation }\end{array}$ & 5 & $05 / 03$ \\
\hline 784 & $\begin{array}{l}\text { O. Pierrard } \\
\text { H. R. Sneessens }\end{array}$ & $\begin{array}{l}\text { Low-Skilled Unemployment, Biased } \\
\text { Technological Shocks and Job Competition }\end{array}$ & 2 & $05 / 03$ \\
\hline 785 & R. Almeida & $\begin{array}{l}\text { The Effects of Foreign Owned Firms on the } \\
\text { Labor Market }\end{array}$ & 2 & $05 / 03$ \\
\hline 786 & $\begin{array}{l}\text { P. Mueser } \\
\text { K. R. Troske } \\
\text { A. Gorislavsky }\end{array}$ & $\begin{array}{l}\text { Using State Administrative Data to Measure } \\
\text { Program Performance }\end{array}$ & 6 & $05 / 03$ \\
\hline 787 & $\begin{array}{l}\text { P. Garibaldi } \\
\text { L. Pacelli } \\
\text { A. Borgarello }\end{array}$ & $\begin{array}{l}\text { Employment Protection Legislation and the Size } \\
\text { of Firms }\end{array}$ & 3 & $05 / 03$ \\
\hline 788 & $\begin{array}{l}\text { F. Büchel } \\
\text { J. R. Frick }\end{array}$ & $\begin{array}{l}\text { Immigrants in the UK and in West Germany - } \\
\text { Relative Income Position, Income Portfolio, and } \\
\text { Redistribution Effects }\end{array}$ & 1 & 06/03 \\
\hline 789 & $\begin{array}{l}\text { J. A. Cabral Vieira } \\
\text { A. R. Cardoso } \\
\text { M. Portela }\end{array}$ & $\begin{array}{l}\text { Recruitment and Pay at the Establishment } \\
\text { Level: Gender Segregation and the Wage Gap } \\
\text { in Portugal }\end{array}$ & 5 & $06 / 03$ \\
\hline 790 & $\begin{array}{l}\text { A. Cigno } \\
\text { A. Luporini } \\
\text { A. Pettini }\end{array}$ & $\begin{array}{l}\text { Hidden Information Problems in the Design of } \\
\text { Family Allowances }\end{array}$ & 3 & 06/03 \\
\hline
\end{tabular}

An updated list of IZA Discussion Papers is available on the center's homepage www.iza.org. 